\title{
PARA UMA COSMÓPOLIS LUSÓFONA DE ESTUDOS CLÁSSICOS
}

\author{
Maria do Céu Fialho * * Universidade de Coimbra. \\ Centro de Estudos \\ Clássicos e Humanísticos
}

RESUMO: O objectivo deste texto é proporcionar uma visão global da evolução e expansão das mobilidades e da colaboração entre as universidades brasileiras e portuguesas, no âmbito dos Estudos Clássicos, nos últimos cinquenta anos, desde as colaborações individuais e pontuais até às colaborações institucionalmente planificadas, tendo em vista a incrementação de trabalho conjunto de pesquisa e de ensino. São já visíveis os resultados desta estratégia e eles atestam as imensas potencialidades que a construção em curso de uma comunidade lusófona de Estudos Clássicos possui.

PALAVRAS-CHAVE: Estudos Clássicos na Lusophonia, evolução, pesquisa conjunta, ensino conjunto, publicações conjuntas, mobilidades.

ABSTRACT: This paper aims to give an overview of the evolution and increasement of the mobilities and collaboration between Brazilian and Portuguese universities, in the field od Classical Studies, in the last half century, since isolated and individual collaborations until contemporary, institutionally planned collaborations, in order to carry out joint research and teaching. Expectable results are already visible and testify the huge pontentialities that the building in progress of a Lusophone community of Classical Studies has.

KEYWORDS: Classical Studies in Lusophony, evolution, joint research, joint teaching, joint publications, mobilities.

O título desta intervenção não representa a formulação de uma finalidade projectada para o futuro, mas reporta-se a uma dinâmica que, vista a partir da contemporaneidade, se iniciou há várias décadas, não menos de quatro, ainda que de modo 
1. Este último viria a ser agraciado em 1993, simultaneamente com um dos maiores escritores portugueses do séc. XX: Vergílio Ferreira. pontual, e que se desenvolveu em crescendo contínuo. É que, talvez com o virar do século, se começou a tomar consciência da força e das potencialidades decorrentes da construção planificada e abrangente, bem como da sedimentação dessa Cosmópolis Lusófona de Estudos Clássicos

É óbvio que essa consciência é filha do estado de maturidade e do patamar de qualidade que os Estudos Clássicos atingiram de ambos os lados do Atlântico, se nos ativermos à realidade brasileira e portuguesa, esperando, em futuro não longínquo, contemplar outros espaços da Lusofonia. Também é óbvio que essa consciência decorre da nossa capacidade e facilidade (que a natureza de língua românica do Português nos confere) de aquisição de competências de multilinguismo. Lemos e conhecemos o que se produz em espanhol, italiano, francês e, por força de anteriores hegemonias de escola e da globalização do inglês, o que em língua inglesa se escreve e, mesmo, em língua alemã.

Enfim, vocacionados, pela nossa presença até então discreta, a sermos 'observatório do mundo', fomos paulatinamente verificando, por cotejo e sem falsas modéstias, que, nas últimas décadas, académicos nossos atingiram, pela qualidade da sua investigação publicada, patamares outrora reservados aos ícones do universo anglo-saxónico. Talvez mais difícil seja interiorizar essa constatação. Mas estou convicta de que essa interiorização é a chave da consciência de uma estratégia comum a desenvolver.

A relação mestre-discípulo, decalcada sobre o modelo colonizador-colonizado, esboroou-se há muito. Lembro que, no que toca à Faculdade de Letras da Universidade de Coimbra, a docência da formação base de Estudos Linguísticos e os correspondentes livros de apoio, levaram a Coimbra, na década de sessenta à década de oitenta, nomes como Evanildo Bechara ou Gladstone Chaves de Mello, Professores Convidados por universidades alemãs e pela Universidade de Coimbra, e posteriormente agraciados com o título de doctores honoris causa pela mesma universidade ${ }^{1}$. Várias geraçōes de futuros classicistas por sua pedagogia se iniciaram, nos anfiteatros da Faculdade de Letras, nos Estudos Linguísticos, com o apoio de bibliografia pedagógica em que os autores brasileiros ocupavam parte substancial.

No que toca aos Estudos Clássicos, em particular, distinguiria nessa colaboração duas fases, correspondendo elas ao 
espírito de épocas diversas. A primeira é marcada pela mobilidade individual, quer espontânea, para participação em alguns congressos, como os da SBEC, de parte a parte, quer feita a convite. Diria que essa fase entra ainda pela década de noventa e apresenta-se, a partir daí, imbricada numa outra modalidade de mobilidade. Ela assenta, essencialmente, no estabelecimento de laços pessoais ou no reconhecimento de pessoas isoladas. É, por natureza, tendencialmente fortuita e descontinuada, ou individualmente fidelizada. Aí, no entanto, mergulham as raízes para o que virá a ser o outro tipo de colaboração futura.

Lembro a permanência mais longa do Prof. Américo da Costa Ramalho, no Rio de Janeiro, na década de setenta. Naturalmente, aí fez discípulos e motivou a mobilidade em sentido contrário de vários doutorandos que viriam a progredir na carreira universitária, essencialmente em universidades do Rio. Os convites endereçados à Prof. Maria Helena da Rocha Pereira surtiram efeito análogo, posterior, entre os anos oitenta e noventa, que trouxeram a Coimbra doutorandos da UFRJ e da UFMG. De notar a simetria do convite que fez vir a Coimbra a Prof. Nelly Novais Coelho.

De convites dirigidos ao Prof. Francisco Oliveira e Maria de Fátima Silva decorre a reciprocidade da presença em Coimbra e direcção de um seminário sobre Teatro Latino (Séneca) da Prof. Zélia Cardoso, em final dos anos noventa.

Esta é uma época de expansão do ensino das Línguas e Literaturas Clássicas na Univ. Portuguesa. A ainda jovem Universidade de Aveiro tem necessidade de afirmar as suas competências, com a leccionação de Literatura Grega por figuras de topo de carreira, prestigiadas. Soube a Prof. Rocha Pereira, uma vez consultada, reforçar uma presença magistral, agora com um enquadramento institucional claro e de frutos garantidos, ao indicar os nomes dos Profs. J. Lins Brandão e J. Alves Torrano para a docência na Universidade de Aveiro.

Estes dois mestres brasileiros ficariam envolvidos nos próprios laços relacionais e de colaboração entre as duas universidades vizinhas e impuseram-se como figuras de referência a alunos, hoje já disseminados pelas escolas secundárias, bem como a colegas, em progressão na carreira ou já no topo. Com eles contámos e contamos, ainda que não de modo sistemático, para colaboração em congressos e seminários. 
No âmbito do Humanismo, decorreram as celebrações, sob a forma de congressos em parceria, dos 400 anos da morte de José de Anchieta, em 1997, entre a USP e o CECH, Coimbra.

Mas é precisamente da escola de Belo Horizonte, UFMG, que, das colaboraçóes pontuais que trazem a Coimbra uma antiga discípula da Prof. Rocha Pereira, a Prof. Tereza Virgínia Barbosa, e que levam, por convite personalizado alguns colegas de Coimbra a Belo Horizonte, que vem a surgir uma das iniciativas que marcam a segunda fase desta dinâmica, e bem mais produtiva: a das colaborações institucionalmente enquadradas e estrategicamente delineadas, com a celebração de convénios e termos aditivos, de onde decorre a leccionação de seminários, circulação de alunos, bem como a organização de congressos e a produção de material escrito, fruto da investigação bilateral. Cito o volume, organizado por M. Fátima Silva e Tereza Barboza, Estudos sobre Mário de Carvalho, Coimbra, IUC/CECH 2012, no contexto dos estudos de Mito e Reescrita e na sequência de convénio entre a Universidade Federal de Minas Gerais e a de Coimbra, mais especificamente, sob a forma de termo aditivo entre os dois grupos de Estudos Clássicos; cito o protocolo mais abrangente do termo aditivo entre o Grupo Pragma-da UFRJ e o Centro de Estudos Clássicos e Humanísticos, com dois congressos luso-brasileiros já organizados, respectivamente na UFRJ, 2012, (dedicado ao tema da Utopia) e CECH, Coimbra, 2013 (dedicado, mais uma vez, à Recepção dos Clássicos em contexto luso-brasileiro), organizados por Maria das Graças Moraes Augusto e Maria de Fátima Silva, havendo já actas publicadas do primeiro ( revista Kleos, 16-17, 2012-2013, UFRJ) e estando o segundo in print, ou os termos aditivos in fieri entre o Grupo LHIA, da UFRJ (Fábio Souza Lessa), e o CECH (M. C. Fialho), dedicado à tensão/ correlação da 'Norma e Transgressão', na dinâmica evolutiva das sociedades, entre a PUC-Inês Ghillardi-Lucena/CECH F. Oliveira (que editaram um livro Representaçôes no Masculino), e entre o Grupo ARCHAI e o CECH.

Os protocolos estabelecidos entre a Universidade de Coimbra e um número considerável de universidades brasileiras facilita, como acordo chapéu, a celebração de acordos a ele abrigados. Ainda entre o Grupo LHIA e o $\mathrm{CECH}$, com agregação de outras instituições portuguesas e brasileiras, se têm 
desenvolvido estudos (e aí o CECH chegou a uma estrutura já com um historial consistente) sobre História da Alimentação. Valorizado fica o Mestrado em "Alimentação: Fontes, Cultura e Sociedade" da FLUC, em que participam as Investigadoras e docentes Prof. Carmen Soares e Paula Barata Dias, organizadoras do I Colóquio Luso-brasileiro de História da Alimentação (31 maio-1 junho de 2013), na sequência de colóquios de parceria já decorridos no ano anterior. Convergem, assim, sinergias de historial mais antigo e sedimentado, do lado brasileiro, com uma área que se quer impor na UC. O próximo passo aponta para a colaboração, no Brasil, em Setembro, UFRJ e Novembro, São Paulo, SENAC.

Destes laços científicos decorre já a existência de volumes temáticos, publicados no Brasil ou nos Classica Digitalia, $\mathrm{CECH}$, as futuras actas, sob forma de volume temático, e o Projecto DIAITA- Património Alimentar da Lusofonia, para a história da alimentação mediterrânico-atlântica desde a Antiguidade, internacional, multidisciplinar, liderado, da parte portuguesa pela Investigadora do $\mathrm{CECH}$ e docente da Universidade de Coimbra Carmen Soares, juntamente com Inês de Ornellas e Castro (Universidade Nova de Lisboa) e Carlos Fabiāo (Universidade de Lisboa), e, da parte brasileira, por Regina Bustamente (LHIA-UFRJ) e Leila Mezan Algranti $(\text { UniCamp })^{2}$. À mesa deste banquete se consolida uma convivialidade científica luso-brasileira, no contexto estratégico de construção de uma cosmópolis de Estudos Clássicos.

A língua une-nos e, por esse mesmo motivo, somos convidados a reflectir e a produzir resultados dessa reflexão sobre o trabalho e soluções de tradução dos Clássicos para português. Teve lugar na Universidade de Coimbra, em Novembro de 2012, o I Encontro Luso-brasileiro org. CECH, M. C.Fialho/ IUC, D. Leão «Traduzir e Publicar os Clássicos», em convergência entre o CECH/Univ. de Coimbra, Univ. de Aveiro, UFRJ, USP, UFMG, UFSC, Annablume ed.. O Colega Prof. Mauri Furlan abriu o espaço da revista Scientia Traductionis para publicação dos resultados do encontro. Aguarda-se a organização, agora do lado de cá, do II Congresso Luso-brasileiro 'Traduzir e Publicar os Clássicos'.

A pragmática da tradução está activa, com a tradução, em equipa, de Diógenes Laércio, coordenada por Gabriele Corne-
2. À data de publicação deste texto este projecto de colaboração lusobrasileira conta já com o reconhecimento das duas grandes fundações nacionais financiadoras $\mathrm{da}$ investigação em Portugal e no Brasil, pois foi aprovado no Programa de Cooperação Científica e Tecnológica FCT-CAPES (2014-2015). 
lli e Delfim Leão, de publicação iminente, a ser editada pelos Classica Digitalia-CECH/IUC/Annablume eds.

Não se trata aqui de um empreendimento isolado. A editora digital do $\mathrm{CECH}$, Classica Digitalia, cuja concepção muito deve ao Prof. Delfim Leão, levou a uma divulgação eficaz, no ciber-espaço, da produção do $\mathrm{CECH}$. Mais uma vez, a convergência de mais-valias gerou sinergias que não têm já retrocesso. Essa dinâmica muito ficou a dever ao Prof. Gabriele Cornelli e ao seu apurado sentido de apostas estratégicas. O cruzar de interesses e motivaçôes que soube aproximar, entre o $\mathrm{CECH}$, a IUC, e a Annablume Eds. Levou ao estabelecimento de parcerias que, nos últimos anos, têm convertido a edição de produção científica portuguesa e a edição de produção científica brasileira em edição bilateral luso-brasileira, que esse não lugar do ciber-espaço tão fortemente potencia. A atestá-lo estão os milhares de descarregamentos anuais, que não são concorrenciais da procura do livro em suporte material.

Abrem-se, simultaneamente, por esse incentivo e novo sentido de colaboração institucionalmente enquadrada, os espaços de publicação das duas margens do Atlântico, no que toca a revistas científicas. Passou a recorrer-se, reciprocamente, à arbitragem científica e à integração bilateral de especialistas em Conselhos Científicos de revistas.

Na nova era do ensino à distância e dos suportes de mobilidade docente, agregada a módulos de pós-graduação, a docência é recíproca, entre universidades brasileiras e portuguesas, bem como o intercâmbio de alunos de Mestrado e Doutoramento. Sublinhe-se, aqui, o papel extraordinariamente activo e eficaz, ao serviço desta mobilidade e na participação em módulos on line do Prof. Gabriele Cornelli e do Grupo e Revista Archai. Assim nos chegue o tempo, salvo de burocracias, para responder aos seus reptos para projectar e executar.

Estamos, de facto, preparando uma geração de jovens classicistas de horizontes bem mais latos que os de há três décadas, no contexto de um novo Renascimento, agora no espaço lusófono, capazes de tomarem nas mãos, com competência e espírito crítico, as rédeas de um futuro em que o confronto de abordagens do Mundo Antigo e o diálogo sobre elas tem implícito um diálogo sobre raízes comuns e sobre condição histórica actual. Diria que, dos tempos de crise saem potenciais de resposta e criatividade nunca imaginados. 
Num universo dominado pela invisível força do grande capital e de novas superpotências bancárias e nacionais, a globalização mostra as suas vantagens e a sua força ameaçadora. E essa é uma realidade que se converteu em factor determinante de consciencialização de que é urgente construir uma Cosmópolis alternativa, fundada em outro poder - no da cultura, da comunicação, do mútuo respeito de troncos da mesma árvore lusófona, cujas raízes mais profundas estão lá onde Homero recitou os seus primeiros hexâmetros e os primeiros filósofos se espantaram com o universo e a pequena partícula pensante que o habita.

O Projecto de Investigação do $\mathrm{CECH}$ tem como tema «Raízes de Identidade Europeia - Pólis/Cosmópolis» - naturalmente, da Antiguidade aos nossos dias, já que a compreensão do Antigo se completa numa melhor e mais crítica compreensão do hodierno, apetrechada por instrumentos a que nós, gente dos Estudos Clássicos, temos acesso privilegiado.

Assim, hoje, deve mobilizar-nos em particular esta Cosmópolis - a Cosmópolis lusófona de Estudos Clássicos, resguardada riqueza e o potencial dialógico das diferenças, que só a globalização cega aplaina e desvaloriza. E a construção ou consolidação dessa Cosmópolis requer intercâmbios e cruzamento de informaçôes, e planeamento de actividades institucionalmente enquadrados, por parte de instituiçōes, de um e outro lado do Atlântico, cuja investigação abranja esse diálogo interdisciplinar entre o passado e o presente.

É bem palpável o progresso imenso feito, nesse sentido e nesta segunda fase, entre o anterior e o actual Congresso da SBEC, com acçôes e congressos geminados, entre várias universidades e Centros de Pesquisa do Brasil e os seus congéneres portugueses, a participação mútua em actividades lectivas, a reflexão conjunta, sob a forma de congresso, acerca da actividade de tradução, as parcerias editoriais, digitais ou em suporte de papel, a criação de sociedades gémeas, como a recém-criada Sociedade Portuguesa de Retórica, estimulada pela Sociedade gémea brasileira, a inclusão recíproca de investigadores em equipas de investigação dos seus congéneres do outro lado do Atlântico.

Falta que conheçamos ainda melhor o que de um e de outro lado se produz cientificamente, para que nos leiamos mais e mais aprendamos uns com os outros - o que facilmente se 
3. À data da publicaçãoo deste texto a candidatura foi já aprovada para 2014-15. atingirá com uma arquitectura planificada e comum no ciber-espaço. Arquitectura essa, aliás, já em marcha, por parte do Grupo Archai e do CECH.

E porque de Coimbra estamos em Brasília, seja de assinalar o Projecto Construindo Cosmópolis, CAPES/FCT que estamos desenvolvendo, entre as duas universidades, entre 20132014. Juntos sabemos e podemos mais, num universo em que o português, se nos olharmos, é língua maioritária. A retórica política, para ser persuasiva, há-de ser musculada.

Saber é poder, a confluência e acção concertada são-no também, e também no domínio da Cultura. Sabia-o Augusto, de quem Portugal e o Brasil (SBEC e APEC, com Museu de Mérida), se preparam para celebrar em 2014 o bimilenário da sua morte.

Saber é poder, esta é a constatação que deixo, como lema final, a ecoar o título da mais recente das obras organizadas em parceria luso-brasileira, em dois volumes: Saberes e poderes no Mundo Antigo, vols. I-II, Fábio Cerqueira, Ana Teresa Gonçalves, Edalaura Medeiros, José Luís Brandão, D. Leão, Coimbra, 2013, Imprensa da Universidade-CECH.

E no contexto deste mesmo congresso, da discussão final, em sede de conferencias, ou da convivialidade à mesa, novos projectos se estão moldando, como o da candidatura a novo Convénio FCT/CAPES, para o intercâmbio de investigadores, da iniciativa de Fabio Faversani, Universidade Federal de Ouro Preto e José Luís Brandão, Universidade de Coimbra-CECH, dedicado a "Literatura e política: construção e difusão do retrato de figuras públicas no mundo antigo/ Literature and Politics: construction and diffusion of public personalities portraits in the ancient world"3. Ou projectos de novos volumes, quer sobre novos aspectos em Plutarco (M. Aparecida Oliveira e Silva, USP, M. Céu Fialho, UC, A. Pérez Jiménez, Univ. Málaga) ou ainda sobre outros aspectos da cultura do Mundo Antigo (Regina Cândido, UERJ, M. C. Fialho, UC).

A Cidade, de Sol e de Sul, cresce, irradia e já não é possível contorná-la.

Recebido em novembro de 2013

Aprovado em dezembro de 2013 